\title{
The Importance of Responsivity Factors in Predicting Reductions in Antisocial Attitudes and Cognitive Distortions Among Adult Male Offenders
}

\author{
Dana Jones Hubbard \\ Cleveland State University, d.j.hubbard@csuohio.edu \\ Jennifer Pealer \\ Northern Kentucky University
}

Follow this and additional works at: https://engagedscholarship.csuohio.edu/clsoc_crim_facpub

Part of the Criminology Commons

How does access to this work benefit you? Let us know!

\section{Original Citation}

Hubbard, D. J., , \& Pealer, J. (2009). The Importance of Responsivity Factors in Predicting Reductions in Antisocial Attitudes and Cognitive Distortions Among Adult Male Offenders. The Prison Journal, 89(1), 79-98. doi:10.1177/0032885508329987

\section{Repository Citation}

Hubbard, Dana Jones and Pealer, Jennifer, "The Importance of Responsivity Factors in Predicting Reductions in Antisocial Attitudes and Cognitive Distortions Among Adult Male Offenders" (2009). Sociology \& Criminology Faculty Publications. 57.

https://engagedscholarship.csuohio.edu/clsoc_crim_facpub/57

This Article is brought to you for free and open access by the Sociology \& Criminology Department at EngagedScholarship@CSU. It has been accepted for inclusion in Sociology \& Criminology Faculty Publications by an authorized administrator of EngagedScholarship@CSU. For more information, please contact library.es@csuohio.edu. 


\title{
The Importance of
}

Responsivity Factors in

Predicting Reductions in

Antisocial Attitudes and

Cognitive Distortions

\section{Among Adult Male Offenders}

\author{
Dana J. Hubbard \\ Cleveland State University, Cleveland, Ohio \\ Jennifer Pealer \\ Northern Kentucky University, Highland Heights
}

The research has demonstrated that cognitive-behavioral treatment programs for offenders work to reduce recidivism. One reason these programs have been found to be effective is that they target one of the "number one" predictors of crime, antisocial attitudes and values. Unfortunately, these programs may not "work" for all offenders. The literature suggests that personal characteristics of offenders, although not directly related to recidivism, may in fact interfere or hinder the ability for the program to "work." This is referred to in the literature as the "responsivity principle." This study seeks to understand the role that personal or responsivity characteristics of offenders play in whether these attitudes and distortions were reduced. This study found that although individual responsivity characteristics alone were not related to whether the program was successful, individuals with a combination of the important responsivity characteristics (e.g., low intelligence, low self-esteem, and history of sexual abuse) were less likely to benefit from the program. In fact, their cognitive distortions were often made worse. Thus, it may be that responsivity should be seen as having a cumulative effect. The more "issues" an offender has, the less likely the treatment will accomplish what it is "supposed to do"-which in this case was to reduce antisocial or cognitive distortions.

Keywords: responsivity; cognitive distortions; antisocial attitudes; corrections 
Correctional programs today have very diverse populations. Several of the most striking differences revolve around mental health issues and personality. These differences have been referred to in the literature as "responsivity factors" in that they may make offenders more or less able to respond to treatment. According to the correctional rehabilitation literature, correctional practitioners should consider assessing these factors and perhaps offer different types of programming based on some of these personal characteristics.

This article summarizes findings from a study of a cognitive-behavioral treatment program, one of the most popular types of correctional programming today. The goal of cognitive-behavioral treatment is to reduce cognitive distortions and/or antisocial attitudes in offenders. Reducing antisocial attitudes and cognitive distortions has been found to be related to reductions in recidivism. This study is unique in that the research addressed here seeks to assess whether various responsivity characteristics are related to the intermediate goal of a reduction in cognitive distortions. We hypothesize that individual offender issues such as depression, low self-esteem, low intelligence, a history of sexual abuse, and certain personality types such as "aggressives" and "neurotics" will be less likely to benefit from the treatment and reduce their cognitive distortions and antisocial attitudes.

\section{Literature Review}

Cognitive-behavioral treatment for offenders is based on the belief that offenders tend to display limited problem solving skills (Ross \& Fabiano, 1985), have antisocial values and attitudes (Jennings, Kilkenny, \& Kohlberg, 1983), and are known to display thinking errors (Yochelson \& Samenow, 1976). Cognitive behavioral strategies, then, teach offenders how to develop self control, manage their anger more appropriately, develop empathy through role playing, improve problem-solving abilities, and develop their level of moral reasoning (Hollin, 1990). If treatment programs can change these cognitive characteristics of offenders, it follows that recidivism rates should be reduced.

In the correctional rehabilitation literature, both individual outcome studies and the numerous meta-analyses have demonstrated that cognitivebehavioral strategies are among the most effective treatment approaches for offenders. One of the most researched cognitive-behavioral programs for offenders is the Reasoning and Rehabilitation program (R and R; Robinson, 1995; Robinson, Grossman, \& Porporino, 1991; Ross, Fabiano, \& Ewles, 1988). Evaluation studies of $R$ and $R$ have all shown consistent effects of 
this cognitive-behavioral program over control groups. Another cognitive treatment program that has been shown to be effective is moral reconation therapy (Little, 2001). Moreover, the meta-analyses have also consistently shown cognitive-behavioral programs to be effective at reducing offender recidivism (Andrews, Zinger, Bonta, Gendreau, \& Cullen, 1990; Antonowicz \& Ross, 1994; Garrett, 1985; Izzo \& Ross, 1990; Lipsey, 1990).

The notion of specific responsivity refers to the idea that individual personal characteristics may make offenders more or less responsive to treatment (Andrews, Bonta, \& Hoge, 1990). Although not a new idea, the labeling of the practice of matching treatment to personal characteristics (responsivity) is relatively new. As early as the 1950s, Freud warned that psychotherapists should be aware that their highly verbal style of therapy was inappropriate for certain offender types such as those with poor verbal abilities (Freud, 1953). Recently, there has been some research indicating that personal characteristics such as intelligence and personality may mediate the effects of treatment. However, despite one study that found that IQ may affect success in cognitivebehavioral treatment (Ross \& Fabiano, 1985), few studies have addressed the issue of responsivity with regard to cognitive-behavioral treatment (Van Voorhis, 1997).

The assumption behind the specific responsivity principle is the idea that not all offenders are alike. Not unlike the general population, people have various characteristics that may affect a person's ability to succeed in treatment. For example, cognitive-behavioral treatment is generally performed in a group setting and targets offenders' attitudes and values. Certain personal characteristics can affect whether an individual understands the treatment, can focus in treatment, and/or has the capacity for change. Unfortunately, despite being repeatedly mentioned in the literature as a principle of effective intervention, little research has been done regarding what personal characteristics are important in determining success in various programs. Several potential responsivity characteristics have been discussed in the literature and include gender, depression, low self-esteem, history of sexual abuse, low intelligence, and personality (see Bonta, 1995; Kennedy \& Serin, 1997; Listwan, Sperber, Spruance, \& Van Voorhis, 2004; Van Voorhis, 1997).

Many researchers have suggested that depression could be an important responsivity characteristic (Bonta, 1995; Kennedy \& Serin, 1997; Van Voorhis, 1997). How depression is related to success or failure however is still not known. Although many researchers have cited it as a potential responsivity factor, there is little research on its effects.

There has been much discussion about the importance of self-esteem as a predictor of criminal behavior; however, there is little discussion about how 
it may work as a responsivity consideration. Perhaps those offenders with low self-esteem might not participate in group therapy and might need more skilled staff members. Again, the role of this characteristic is not yet known.

A history of sexual abuse is often discussed in the literature as a risk factor for crime in both males and females (see Lowenkamp \& Latessa, 2004). Yet it is also likely an important responsivity consideration. For example, a past history of sexual abuse is related to depression, posttraumatic stress disorder, and low self-esteem (see Nagy et al., 1995). In terms of a responsivity consideration, perhaps a person with a history of sexual abuse might be less likely to participate in the treatment and more likely to withdraw.

Personality is a responsivity characteristic that has actually received attention. One of the earliest studies of responsivity in corrections occurred in the 1960s, led by James Douglas Grant (1965). In this study, called the PICO project, inmates were categorized as either "amenable" or "non-amenable." Amenable inmates were highly motivated, mature, and verbally skilled. Conversely, the non-amenables were less verbally skilled and unmotivated to participate in treatment. The amenables tended to have lower recidivism rates than the non-amenables. Moreover, in another study conducted by Grant (1965), he found that low-maturity inmates respond better to highly structured treatment programs.

Interpersonal maturity theory was created in the 1950s by Sullivan, Grant, and Grant (1957). These psychologists attempted to explain differences in psychological development to differentiate treatment plans for juveniles under correctional supervision (Warren, 1983). They found they could classify juveniles into one of four levels of interpersonal maturity, ranging from I Level 2 to I Level 5. Specifically, I Level refers to the way in which a person views himself or herself and the world around him or her (Warren, 1983). In addition to an interpersonal maturity scale, Warren (1983) defined nine personality types. People, she claimed, fall into one of these nine subtypes: unsocialized aggressive (AA), unsocialized passive (AP), immature conformist (CFM), cultural conformist (CFC), manipulator/pragmatist (MP), neurotic acting out (NA), neurotic anxious (NX), situational emotional (SE), and cultural identifier (CI).

What developed from Warren's (1983) work on interpersonal maturity and personality is a comprehensive classification system designed to measure interpersonal maturity and personality subtypes call the Jesness Inventory. Although originally used on juveniles, revisions were made to the instrument in 1972 that made the assessment more relevant to adults and females (Jesness, 1988). Research has indicated that these personality subtypes are predictive of criminal behavior (Palmer, 1975). For example, Van Voorhis (1994) found that the nine personality subtypes could be collapsed 
into four categories consisting of aggressives (AA, CFC, and MP), neurotics (NA and NX), dependents (AP and CFM), and situationals (SE and CI). She found that aggressives were more likely to display aggressive behaviors in the prison camp and penitentiary than were the other personality subtypes. Finally, Johnson-Listwan (2001) found that neurotics and aggressives were significantly more likely to engage in criminal behavior. Although there is research indicating personality is a risk factor for crime, there is still little research with regard to how it operates as a responsivity consideration.

In addition to maturity and personality, other responsivity characteristics have been shown to mediate treatment success. For example, Ross and Fabiano (1985) found that intelligence was related to success in a cognitivebehavioral treatment program. They found that offenders with intelligence levels lower than 85 might not be successful in a cognitive program. Offenders with lower intelligence levels might not have the ability to understand cognitive curriculums. For example, many curriculums emphasize learning the difference between thoughts and feelings and learning to act only on thoughts rather than feelings. This might be too difficult a concept to grasp for those offenders with low IQs. Thus, they may appear to be uninterested or unsuccessful when they cannot understand the material. Despite this one study, little research has addressed the issue of intelligence as a responsivity consideration.

Although there are studies indicating that personal characteristics and abilities of offenders are related to success in treatment, far more research is needed. Given the fact that cognitive-behavioral treatment has been found to be effective and that many correctional treatment agencies have implemented these types of programs, it is important to examine potential responsivity factors with regard to this type of treatment.

\section{Method}

This study was part of a larger study funded by the Ohio Office of Criminal Justice Services. The data were primarily collected by the authors of this study and correctional center staff. Participants in this study were adult male felony probationers who were sentenced to a community correctional center in Ohio. The sample consisted of men entering the program, March 2000 through January 2001. The correctional center is a 100-bed communitybased correctional facility serving primarily adult male felony probationers.

Offenders at this facility receive approximately 120 hours of Corrective Thinking. The Corrective Thinking curriculum developed by Rogie Spon 
(1999) is based on the work of Yochelson and Samenow (1976, 1977). Instead of thinking errors, however, the curriculum teaches offenders how to recognize their "barriers in thinking" and replace them with the appropriate "correctives." The curriculum consists of a series of exercises aimed at teaching the offenders the nine barriers in thinking and the nine correctives. For example, one of the nine barriers is "victim stance." The corrective for this barrier is "taking responsibility." Participants go through a series of exercises designed to change their thinking from blaming someone else for their lives to taking responsibility for the choices they make. The program is generally considered a cognitive "restructuring" program rather than a skill building program. However, there are some exercises that involve role playing and the practicing of new behaviors. Currently, there is no research on the effectiveness of this particular cognitive-behavioral program. By contrast, cognitive-behavioral programming in general has been found to be effective with offender populations (see Robinson, 1995; Robinson et al., 1991; Ross et al., 1988).

Other programming includes chemical dependency, GED classes, vocational assistance, family services, and life skills training. Although all offenders in the above treatment program were required to participate in the cognitive treatment groups, participation in this study was voluntary. Staff at each study site explained the study to offenders on intake into each program, and offenders were asked to participate. The offenders were then asked to sign a release if they agreed to participate in the study.

The first offenders in the sample entered the treatment program in April 2000. The last offenders included in the study entered the programs in September 2001. The total sample consists of 257 men.

\section{Assessment Measures}

Table 1 shows the assessment measures for the present study. The responsivity variables were personality, IQ, self-esteem, depression, and abuse. These data were derived from a survey administered at intake into the program. ${ }^{1}$ In addition, a responsivity scale was created that combined all the responsivity measures and was coded so that greater scores indicate more barriers to success.

Personality. The personality types of the offenders were determined by administering the Jesness Inventory (Jesness, 1996). The inventory is a brief true and false questionnaire to determine the interpersonal maturity level of the individual. This assessment was chosen because of psychometric research that has yielded positive validity and reliability tests (see 
Table 1

Assessment Measures

\begin{tabular}{lll}
\hline Responsivity Measures & Control Variables & Outcome Measures \\
\hline $\begin{array}{l}\text { Personality: Jesness } \\
\text { Inventory }\end{array}$ & Age & Cognitive Distortions \\
Intelligence: Culture Fair & $\begin{array}{l}\text { Risk level } \\
\text { Level of Service } \\
\text { Inventory }\end{array}$ & $\begin{array}{l}\text { How I Think Questionnaire } \\
\text { Behavioral Referents } \\
\text { How I Think Questionnaire }\end{array}$ \\
$\begin{array}{l}\text { Self-Esteem: Rosenburg's } \\
\quad \text { Self-Esteem Scale }\end{array}$ & How I Think Subscales \\
Depression: Center for & & \\
$\quad$ Epidemiological & & \\
Studies Scale & & \\
Abuse: Self-report & & \\
$\quad$ questionnaire & & \\
Responsivity Scale & & \\
Personality: & & \\
1 = situationals & & \\
$2=$ dependents & & \\
$3=$ neurotics & & \\
$4=$ aggressives & & \\
Low intelligence & & \\
Low self-esteem & & \\
Depression & & \\
History of abuse & & \\
\hline
\end{tabular}

Carbonell, 1983; Jesness, 1996; Van Voorhis, 1994). The results yield the level of maturity and the personality type of the respondent. Although there are nine different types of personality, they can be collapsed into four different categories-aggressives, neurotics, dependents, and situationals (Van Voorhis, 1994).

The aggressives (AA, CFC, and MP) tend to act in a physical and antisocial manner. They feel alienated and have antisocial attitudes. The neurotics (NA and NX) tend to act out in antisocial ways when they are anxious. Dependents (AP and CFM) have conforming behavior but are more likely to be a follower including following criminal others. Situationals (SE and CI) have positive relationships and mostly conform. However, they can be naïve. Research has shown that neurotics and aggressive are more likely to recidivate (Johnson-Listwan, 2001; Van Voorhis, 1994). 
Although personality has been found to be related to success in treatment (Warren, 1983), very little research has been conducted to examine personality characteristics on success in a cognitive-behavioral program (Van Voorhis, 1997). Accordingly, we included this measure of personality in our responsivity scale to gauge if personality acts in combination with other responsivity characteristics in predicting improvement in posttest scores. It is hypothesized that neurotics and aggressives would have the most "issues," and thus the scale was coded as such.

Intelligence. As Ross and Fabiano (1985) found, intelligence might help to explain some of the variation in success in a cognitive-behavioral program. Specifically, it is theorized that those individuals with lower IQs will not be able to completely understand the material and thus will have poorer outcomes regarding success in treatment (Ross \& Fabiano, 1985). However, there have been some who have argued that intelligence testing is not really measuring intelligence but other extraneous influences. As such, we included a measure of intelligence as determined by the Culture Fair Intelligence Test (Catell \& Catell, 1963). The test has been studied extensively with both reliability and validity data supportive of the test. This test was specifically utilized because it measures an individual's intelligence while minimizing the influence of verbal fluency, culture climate, and educational level.

Self-esteem. Research on the correctional population has consistently shown that self-esteem is not a risk factor for criminal behavior (Andrews \& Bonta, 1999). However, the influence of self-esteem, or the lack thereof, might be a responsivity factor for this population. Specifically, those with low levels of self-esteem are more likely to have greater difficulty in successfully participating in treatment and thus will have a smaller difference between their pre- and posttest measures. To measure the influence of selfesteem, participants were tested using Rosenburg's Self-Esteem Scale (Rosenburg, 1979). The instrument was developed by Morris Rosenburg and was originally validated and normed on high school students but has since been validated on a variety of populations (see Fleming \& Courtney, 1984). This 10-item scale is measured so that the higher the score, the higher the self-esteem. Items are given a weight and added up so that individuals can score from 1 to 30 on the test. For the purposes of the responsivity scale, the Self-Esteem Scale was reverse coded.

Depression. Depression is another area where research has found that it is not a major predictor of recidivism (Andrews \& Bonta, 1999). However, 
other researchers have argued that depression might be a barrier that should be addressed if one is to be successful in treatment (Bonta, 1995; Kennedy \& Serin, 1997; Van Voorhis, 1997). It is hypothesized that offenders who score high on a depression scale will be less likely to participate in groups and thus we be less likely to successful complete programming. This inability to fully participate in programming will result in a smaller difference in pre- and posttest measures of cognitive distortions.

The measure of depression that was used for our study was the Center for Epidemiologic Studies Depression Scale (CESD), which is a 20-item selfreport instrument. The scale is widely used to distinguish depressed individuals and nondepressed individuals in nonclinical settings (Radloff, 1977). Research using the scale has found it to be valid and reliable (see FechnerBates, Coyne, \& Schwenk, 1994; Lewinson, Seeley, Roberts, \& Allen, 1997). The scale is coded so that higher scores indicate higher levels of depression.

Abuse. A history of sexual abuse has been found to be correlated with depression, PTSD, and low self-esteem. In addition, sexual abuse has been discussed as a potential responsivity factor (Andrews \& Bonta, 1999; Lowencamp \& Latessa, 2004). Data were gathered on past history of sexual abuse through official records (client files). Data were coded as yes or no.

Control variables. We included two control variables in our study: age and risk level. As previous research has shown, age is a demographic characteristic that predicts outcome for the correctional population.

The risk level of the individual was also used as a control variable. As research has shown, the risk level of the offender is related to success in correctional programs (Andrews \& Bonta, 1999). Furthermore, the risk level of the offender can be predicted through actuarial risk assessments instruments (Bonta, 1996; Jones, 1996). Accordingly, to control for risk level of the probationer, we included the Level of Service Inventory-Revised (LSI) score. This instrument is a standardized and objective risk or need instrument that assesses an offender's likelihood of recidivism (Andrews \& Bonta, 1999). The instrument is dynamic in that is measures risk factors that might change with appropriate intervention. The LSI is coded so that higher scores indicate a greater propensity for criminal behavior. The information to score the LSI was obtained through a semistructured interview with the offender at intake.

Outcome measure. For the present study, we focused on the difference in pretest and posttest scores for the How I Think Questionnaire (Barriga \& Gibbs, 1999). The How I Think Questionnaire is a self-report instrument that 
measures self-serving cognitive distortions. Cognitive distortions are inaccurate ways of attending to or conferring meaning on experiences (Barriga \& Gibbs, 1999). Research has indicated that cognitive distortions might contribute to antisocial or criminal behavior (Yochelson \& Samenow, 1976). Thus, programs should address these antisocial ways of thinking if recidivism is to be reduced. In addition, participation in a cognitive-behavioral program should reduce the levels of cognitive distortions among the participants.

The How I Think instrument measures four cognitive distortions: selfcenteredness (according such status to one's own views that the opinions of others are not considered), blaming others (misattributing blame to outside sources), minimizing/mislabeling (believing that antisocial behavior is acceptable, admirable, or causes no real harm), and assuming the worst (assuming that improvement is impossible or considering a worst case scenario).

The How I Think Questionnaire also depicts four behavioral referents scales that are manifested from the cognitive distortions: Opposition/Defiance, Physical Aggression, Lying, and Stealing. From these subscales, three summary scores can be computed. The overt scale is computed by averaging the Opposition/Defiance and Physical Aggression means. The covert scale is computed by averaging the Lying and Stealing means. The overall How I Think score is computed by averaging the means of all eight subscales. Higher scores indicate higher levels of cognitive distortions.

\section{Statistical Analyses}

We examined 11 different scales within the How I Think Questionnaire: Self-Centeredness, Blaming Others, Minimizing, Assuming the Worst, Oppositional Defiance, Physical Aggression, Lying, Stealing, Overt Behaviors, Covert Behaviors, and the overall How I Think scale. Linear regression analysis was used to analyze the continuous outcome variables. In each analysis, the predictor variables were entered simultaneously, where each was tested controlling for the other variables in the equation. Linear regression allows us to determine the predictive ability of each variable when holding the other variables constant.

\section{Results}

\section{Sample Characteristics}

Table 2 reveals the characteristics of the sample. During the evaluation period, there were 257 men who entered the community correctional center. 
Table 2

Sample Characteristics

\begin{tabular}{|c|c|c|}
\hline Variable & $n$ & $\%$ \\
\hline \multicolumn{3}{|l|}{ Race } \\
\hline White & 162 & 73.0 \\
\hline Non-White & 60 & 27.0 \\
\hline \multicolumn{3}{|l|}{ Marital status } \\
\hline Single & 177 & 79.7 \\
\hline Married, living with & 45 & 20.3 \\
\hline \multicolumn{3}{|l|}{ Education level } \\
\hline Less than high school & 120 & 56.6 \\
\hline High school or GED & 90 & 42.6 \\
\hline College degree & 2 & 0.8 \\
\hline \multicolumn{3}{|l|}{ Children younger than 18} \\
\hline Yes & 105 & 47.5 \\
\hline No & 116 & 52.5 \\
\hline \multicolumn{3}{|l|}{ Prior arrest } \\
\hline Yes & 207 & 92.0 \\
\hline No & 18 & 8.0 \\
\hline \multicolumn{3}{|l|}{ Previous prison } \\
\hline Yes & 51 & 23.3 \\
\hline No & 168 & 76.7 \\
\hline \multicolumn{3}{|l|}{ Previous drug treatment } \\
\hline Yes & 116 & 52.3 \\
\hline No & 106 & 47.7 \\
\hline \multicolumn{3}{|l|}{ History of drug problem } \\
\hline Yes & 215 & 96.8 \\
\hline No & 7 & 3.2 \\
\hline \multicolumn{3}{|l|}{ Risk level $^{\mathrm{a}}$} \\
\hline Low & 4 & 1.8 \\
\hline Low to moderate & 27 & 12.3 \\
\hline Moderate & 135 & 61.6 \\
\hline Moderate to high & 47 & 21.5 \\
\hline High & 6 & 2.7 \\
\hline
\end{tabular}

a. $M=29.51$.

Of those men, a clear majority was White (73.0\%) and single (79.7\%). Most of the men were uneducated $(56.6 \%)$ and did not have any dependents younger than $18(52.5 \%)$.

Our sample appeared to have previous contact with criminal justice system. For example, $92.0 \%$ had been previously arrested, with $23.3 \%$ having a previous period of incarceration within a prison. Even though $96.8 \%$ of the 
Table 3

Responsivity Characteristics of the Sample

\begin{tabular}{lrrrrr}
\hline Variable & $n$ & $\%$ & & & \\
\hline $\begin{array}{l}\text { History of sexual } \\
\text { abuse }\end{array}$ & & & & & \\
$\quad$ Yes & 8 & 3.6 & & & \\
$\quad$ No & 217 & 96.4 & & & \\
Jesness Inventory & 49 & 23.1 & & & \\
$\quad$ Aggressives & 96 & 45.3 & & & \\
$\quad$ Neurotics & 17 & 8.0 & & & \\
$\quad$ Dependents & 50 & 23.6 & & & \\
$\quad$ Situationals & $n$ & Min & Max & & \\
\hline & 221 & 6 & 27 & 18.23 & 4.31 \\
& 221 & 1 & 19 & 100.80 & 16.76 \\
\hline Self-Esteem Scale & 223 & 45 & 151 & & \\
Depression Scale & 206 & 18.00 & 191.00 & 128.32 & 22.95 \\
IQ & & & & & \\
Responsivity Scale & & & & \\
\hline
\end{tabular}

sample reported a history of drug problems, only $52.3 \%$ of the participants had received treatment for their substance abuse.

When examining the risk data, it appeared that most of the individuals were in need of some form of correctional intervention to reduce their risk of recidivism. For example, approximately $85 \%$ of the participants scored as "moderate" risk or higher on the LSI, with the average risk score being 29.51.

The responsivity characteristics of the probationers are shown in Table 3. An overwhelming majority of offenders (96.4\%) did not have a history of sexual abuse in their case files. However, this is not surprising given that this information was obtained from cases files and it may be that information pertaining to abuse was not in the files. In addition, some participants may have failed to report this information when asked by the program staff. Concerning the personality characteristics of the sample, more offenders were classified as either neurotics $(45.3 \%)$ or aggressives $(23.1 \%)$. These personality types tend to have characteristics that would appear to be barriers for success in treatment. For example, aggressives typically report feelings of alienation and hostility, whereas neurotics tend to be anxious and insecure.

The mean score on the Self-Esteem Scale was 18.23 out of a possible 30. A 30 on the score would indicate the highest possible self-esteem. Scores on the CESD ranged from 1 to 19 (out of a possible 20), with a mean score of 8.68. 
Table 4

Paired-Sample $t$ Tests for the How I Think Questionnaire

\begin{tabular}{|c|c|c|c|c|c|}
\hline Scale & No. of Pairs & Time $1 M$ & Time $2 M$ & $t$-Value & Sig. \\
\hline \multicolumn{6}{|l|}{ Cognitive distortions } \\
\hline $\begin{array}{r}\text { Self-Centered } \\
\text { (range 0-6) }\end{array}$ & 58 & 3.05 & 4.24 & -8.787 & .000 \\
\hline $\begin{array}{l}\text { Blaming Others } \\
\text { (range 0-6) }\end{array}$ & 58 & 3.09 & 4.28 & -7.180 & .000 \\
\hline $\begin{array}{l}\text { Minimizing/Mislabeling } \\
\text { (range 0-6) }\end{array}$ & 56 & 4.23 & 3.07 & 7.554 & .000 \\
\hline $\begin{array}{l}\text { Assuming the Worst } \\
\text { (range 0-6) }\end{array}$ & 57 & 2.45 & 4.74 & -15.571 & .000 \\
\hline \multicolumn{6}{|l|}{ Behavioral referents } \\
\hline $\begin{array}{l}\text { Opposition-Defiance } \\
\text { (range 0-6) }\end{array}$ & 56 & 3.14 & 4.20 & -6.380 & .000 \\
\hline $\begin{array}{l}\text { Physical Aggression } \\
\text { (range 0-6) }\end{array}$ & 58 & 3.11 & 4.17 & -6.572 & .000 \\
\hline Lying (range 0-6) & 57 & 3.42 & 3.90 & -3.640 & .001 \\
\hline Stealing (range 0-6) & 59 & 3.07 & 4.17 & -9.209 & .000 \\
\hline \multicolumn{6}{|l|}{ Summary scores } \\
\hline Covert (range 1-6) & 56 & 2.47 & 3.00 & -5.670 & .000 \\
\hline Overt (range 1-6) & 53 & 3.13 & 4.19 & -6.588 & .000 \\
\hline How I think (range 1-6) & 50 & 3.20 & 4.13 & -6.585 & .000 \\
\hline
\end{tabular}

Higher scores on this scale indicate that the offender is highly depressed. Finally, intelligence scores ranged from 45 to 151 , with a mean score of 100.80 .

\section{Change in Antisocial Attitudes}

The participants were given the How I Think Questionnaire at intake and discharge from the program. As a result of participating in treatment, there should be a reduction in antisocial attitudes. To determine if the program reduced the cognitive distortions of the offenders, paired-sample $t$ tests were conducted. Because the scales were coded so that higher scores equate to higher levels of cognitive distortions, one would expect to see the posttest score to be smaller than the pretest score. As shown in Table 4, there were significant differences between the pre- and posttests. However, the Time 2 score actually increased significantly for all the scales except for Minimizing. That is, participation in the program decreased the offenders minimizing but actually increased the remaining cognitive distortions and the antisocial behaviors that result from these cognitive distortions. Is this finding just an anomaly, or did the program actually make the offenders 
Table 5

Results of Linear Regression Predicting Differences in Cognitive Distortions (Individual Responsivity)

\begin{tabular}{|c|c|c|c|c|c|c|c|c|c|c|c|c|}
\hline \multirow[b]{3}{*}{ Variable } & \multicolumn{3}{|c|}{ Self-Centeredness } & \multicolumn{3}{|c|}{ Blaming Others } & \multicolumn{3}{|c|}{ Minimizing } & \multicolumn{3}{|c|}{$\begin{array}{l}\text { Assuming } \\
\text { the Worst }\end{array}$} \\
\hline & & $t-$ & & & $t-$ & & & $t-$ & & & $t-$ & \\
\hline & $B$ & Value & $p$ & $B$ & Value & $p$ & $B$ & Value & $p$ & $B$ & Value & $p$ \\
\hline onstant & - & -3.468 & .001 & - & -2.803 & .008 & - & -1.426 & .162 & - & -1.576 & .124 \\
\hline Risk level & .311 & 1.956 & .058 & .179 & 1.287 & .206 & .277 & 2.004 & .053 & .240 & 1.450 & .156 \\
\hline Age & .219 & 1.124 & .268 & .068 & 0.416 & .680 & -.028 & -0.170 & .866 & -.034 & -0.171 & .865 \\
\hline Abuse & .024 & 0.159 & .874 & .138 & 1.023 & .313 & .132 & 0.982 & .333 & .094 & 0.585 & .562 \\
\hline Personality & .119 & 0.738 & .465 & .116 & 0.817 & .419 & .001 & 0.006 & .995 & .190 & 1.119 & .271 \\
\hline Depression & .099 & 0.489 & .628 & 409 & 2.328 & .026 & .294 & 1.661 & .105 & .168 & 0.795 & .432 \\
\hline IQ & .244 & 1.585 & .122 & .027 & 0.202 & .841 & .025 & 0.180 & .858 & -.151 & -0.930 & .359 \\
\hline Self-esteem & .175 & 0.939 & .354 & .229 & 1.366 & .180 & .321 & 1.929 & .062 & .049 & 0.242 & .810 \\
\hline$F$ & 1.936 & & & 3.738 & & & 3.625 & & & 1.093 & & \\
\hline$p$ & .092 & & & .004 & & & .005 & & & .389 & & \\
\hline
\end{tabular}

Table 6

Results of Linear Regression Predicting Differences in Cognitive Distortions (Individual Responsivity)

\begin{tabular}{|c|c|c|c|c|c|c|c|c|c|c|c|c|}
\hline \multirow[b]{3}{*}{ Variable } & \multicolumn{3}{|c|}{$\begin{array}{l}\text { Oppositional } \\
\text { Defiance }\end{array}$} & \multicolumn{3}{|c|}{$\begin{array}{l}\text { Physical } \\
\text { Aggression }\end{array}$} & \multicolumn{3}{|c|}{ Lying } & \multicolumn{3}{|c|}{ Stealing } \\
\hline & & $t-$ & & & $t-$ & & & $t-$ & & & $t$-Value & \\
\hline & $B$ & Value & $p$ & $B$ & Value & $p$ & $B$ & Value & $p$ & $B$ & Value & $p$ \\
\hline onstant & - & -1.782 & .084 & - & -2.262 & .030 & - & -2.832 & .008 & - & -2.726 & .010 \\
\hline Risk level & .176 & 1.188 & .243 & .312 & 2.043 & .048 & .191 & 1.295 & .204 & .321 & 2.274 & .029 \\
\hline Age & .034 & 0.198 & .844 & .039 & 0.205 & .839 & .071 & 0.400 & 691 & .022 & 0.134 & .894 \\
\hline Abuse & .154 & 1.064 & .295 & .069 & 0.408 & .634 & .016 & 0.112 & .912 & .168 & 1.234 & .225 \\
\hline Personality & .058 & 0.378 & .708 & .123 & 0.791 & .434 & .119 & 0.787 & .436 & .167 & 1.160 & .254 \\
\hline Depression & .310 & 1.624 & .114 & .171 & 0.861 & .395 & .157 & 0.855 & .398 & .432 & 2.428 & .020 \\
\hline IQ & -.135 & -0.912 & .368 & -.014 & -0.095 & .925 & .157 & 1.291 & .205 & .004 & 0.033 & .974 \\
\hline Self-esteem & .327 & 1.856 & .072 & .249 & 1.370 & .179 & .333 & 1.880 & .068 & .023 & 0.133 & .895 \\
\hline$F$ & 2.755 & & & 2.182 & & & 2.685 & & & 3.309 & & \\
\hline$p$ & .022 & & & .059 & & & .024 & & & .008 & & \\
\hline
\end{tabular}

have higher levels of antisocial thinking? Could it have been that there were other factors that might affect the increase in the posttest score?

Models Predicting the Difference in the Measures of Cognitive Distortions

According to the responsivity principle, offenders have certain factors that should be addressed either before programming or while in programming if 
Table 7

Results of the Linear Regression Predicting Differences in the How I Think Subscales (Individual Responsivity)

\begin{tabular}{|c|c|c|c|c|c|c|c|c|c|}
\hline \multirow[b]{2}{*}{ Variable } & \multicolumn{3}{|c|}{ Covert } & \multicolumn{3}{|c|}{ Overt } & \multicolumn{3}{|c|}{ How I Think } \\
\hline & $B$ & $t$-Value & $p$ & $B$ & $t$-Value & $p$ & $B$ & $t$-Value & $p$ \\
\hline Constant & - & -3.039 & .004 & - & -1.662 & .106 & - & -2.161 & .039 \\
\hline Risk level & .254 & 1.763 & .087 & .231 & 1.471 & .151 & .238 & 1.572 & .126 \\
\hline Age & .065 & 0.381 & .706 & -.007 & -0.035 & .972 & .036 & 0.203 & .841 \\
\hline Abuse & .099 & 0.709 & .483 & .130 & 0.864 & .394 & .190 & 1.286 & .208 \\
\hline Personality & .084 & 0.571 & .572 & .077 & 0.485 & .631 & .002 & 0.011 & .991 \\
\hline Depression & .315 & 1.769 & .086 & .344 & 1.652 & .108 & .447 & 2.306 & .028 \\
\hline IQ & .137 & 0.987 & .330 & -.125 & -0.786 & .438 & -.061 & -0.400 & .692 \\
\hline Self-esteem & .238 & 1.383 & .175 & .244 & 1.317 & .197 & .232 & 0.324 & .195 \\
\hline$F$ & 3.235 & & & 2.454 & & & 3.211 & & \\
\hline$p$ & .009 & & & .078 & & & .012 & & \\
\hline
\end{tabular}

the offender is to have success with treatment. To determine if individual personal characteristics (or responsivity characteristics) might help to account for the increase in cognitive distortions, the difference between preand posttest scores for the How I Think Questionnaire was regressed on age, risk level, and the individual responsivity variables (Tables 5 to 7). Of all the individual responsivity factors, only depression was found to be significantly related to a difference in cognitive distortions. That is, those individuals who scored higher on the depression scale had a bigger reduction in the Blaming Others scale (meaning less likely to blame others), the Stealing scale (meaning less likely to have attitudes supporting stealing), and the overall How I Think score even controlling for level of risk of recidivating. It is surprising that this is the opposite of what we expected to find. It appears as if the treatment performed better for depressed individuals than nondepressed individuals. It should be noted that none of the other individual responsivity factors were related to a difference in cognitive distortions.

In addition to examining the various individual responsivity variables and their relationship to a difference in cognitive distortions, we also examined whether a combination of responsivity issues was related to success. Thus, the difference between pre- and posttest scores for How I Think was regressed on age, risk level, and the responsivity scale (see Tables 8 to 10). Of the four cognitive distortions, three models resulted in a statistically significant finding — the Self-Centeredness, Blaming Others, and Minimizing 
Table 8

Results of Linear Regression Predicting Differences in Cognitive Distortions (Pre- and Posttests)

\begin{tabular}{|c|c|c|c|c|c|c|c|c|c|c|c|c|}
\hline \multirow[b]{3}{*}{ Variable } & \multicolumn{3}{|c|}{ Self-Centeredness } & \multicolumn{3}{|c|}{ Blaming Others } & \multicolumn{3}{|c|}{ Minimizing } & \multicolumn{3}{|c|}{ Assuming the Worst } \\
\hline & & $t-$ & & & $t-$ & & & $t-$ & & & $t-$ & \\
\hline & $B$ & Value & $p$ & $B$ & Value & $p$ & $B$ & Value & $p$ & $B$ & Value & $p$ \\
\hline Constant & - & -0.624 & .568 & - & -0.066 & .948 & - & 1.158 & .254 & - & -1.838 & .074 \\
\hline Age & .150 & 1.065 & .293 & .054 & 0.353 & .726 & -.018 & -0.119 & .906 & -.089 & -0.560 & .578 \\
\hline Risk level & .273 & 1.932 & .060 & .183 & 1.203 & .236 & .280 & 1.885 & .067 & .227 & 1.424 & .162 \\
\hline Responsivity & -.454 & -3.419 & .001 & -.372 & -2.594 & .013 & -.310 & -2.193 & .034 & -.079 & -0.515 & .610 \\
\hline$F$ & 5.116 & & & 3.070 & & & 3.592 & & & 1.241 & & \\
\hline$p$ & .002 & & & .038 & & & .021 & & & .308 & & \\
\hline
\end{tabular}

Table 9

Results of the Linear Regression Predicting Differences in Behavioral Referents (Pre- and Posttests)

\begin{tabular}{|c|c|c|c|c|c|c|c|c|c|c|c|c|}
\hline \multirow[b]{3}{*}{ Variable } & \multicolumn{3}{|c|}{$\begin{array}{l}\text { Oppositional } \\
\text { Defiance }\end{array}$} & \multicolumn{3}{|c|}{$\begin{array}{c}\text { Physical } \\
\text { Aggression }\end{array}$} & \multicolumn{3}{|c|}{ Lying } & \multicolumn{3}{|c|}{ Stealing } \\
\hline & & $t-$ & & & $t-$ & & & $t-$ & & & $t-$ & \\
\hline & B & Value & $p$ & $B$ & Value & $p$ & B & Value & $p$ & B & Value & $p$ \\
\hline Constant & - & -0.272 & .787 & - & -1.141 & 260 & - & 1.093 & .281 & - & -1.117 & .270 \\
\hline Age & .039 & 0.251 & .803 & .006 & 0.041 & 968 & -.021 & -0.145 & .886 & . 034 & 0.230 & .819 \\
\hline Risk level & .192 & 1.237 & .223 & .329 & 2.159 & .037 & .168 & 1.177 & 246 & .317 & 2.127 & .039 \\
\hline Responsivity & -.314 & -2.086 & .044 & -.182 & -1.266 & .212 & -.467 & -3.463 & .001 & -.285 & -2.029 & .049 \\
\hline$F$ & 2.283 & & & 2.639 & & & 5.228 & & & 3.501 & & \\
\hline$p$ & .094 & & & .062 & & & .004 & & & .024 & & \\
\hline
\end{tabular}

scales. For each of the three models, the responsivity scale was significant $(p=.05)$ and in the predicted direction, indicating that offenders with more responsivity issues had smaller differences in the pretest and posttest scores. Furthermore, an examination of the betas reveals that the responsivity scale was a stronger predictor in the differences between scores than the risk level of the offenders.

When examining the behavioral referent scales, the responsivity scale was a significant predictor for the Lying and Stealing scales (Table 9). Again, those offenders who had more responsivity issues had a smaller prosocial change attitudes that would result in someone lying and stealing.

The How I Think Questionnaire also has summary scales for Covert Behaviors, Overt Behaviors, and the overall How I Think scale. Our measure 
Table 10

Results of the Linear Regression Predicting Differences in the How I Think Subscales (Pre- and Posttests)

\begin{tabular}{|c|c|c|c|c|c|c|c|c|c|}
\hline \multirow[b]{3}{*}{ Variable } & \multicolumn{3}{|c|}{ Covert } & \multicolumn{3}{|c|}{ Overt } & \multicolumn{3}{|c|}{ How I Think } \\
\hline & \multicolumn{3}{|c|}{$t-$} & \multicolumn{3}{|c|}{$t-$} & \multicolumn{3}{|c|}{$t-$} \\
\hline & $B$ & Value & $p$ & $B$ & Value & $p$ & $B$ & Value & $p$ \\
\hline Constant & - & 0.375 & .709 & - & -0.754 & .455 & - & -.0567 & .574 \\
\hline Age & .021 & 0.149 & .882 & .036 & 0.230 & .820 & .086 & 0.556 & .582 \\
\hline Risk level & .238 & 1.654 & .106 & .262 & 1.649 & .108 & .274 & 1.761 & .087 \\
\hline Responsivity & -.453 & -3.340 & .002 & -.269 & -1.755 & .088 & -.385 & -2.557 & .015 \\
\hline$F$ & 5.434 & & & 2.315 & & & 3.694 & & \\
\hline$p$ & .003 & & & .092 & & & .021 & & \\
\hline
\end{tabular}

of responsivity issues was a significant predictor in two relationships-Covert Behaviors and the overall How I Think scale (see Table 10). Offenders who had more responsivity issues showed lower reduction in the pre- and posttest measures of covert behavior. That is, offenders with more barriers were less likely to report a reduction in nonconfrontational behaviors. Furthermore, the strength of the responsivity predictor was double that of the risk predictor. In addition, offenders who reported having multiple responsivity issues also had a smaller reduction in the difference between the two measures of the overall How I Think scale, which means they were less likely to extinguish externalizing psychopathology.

\section{Discussion}

Responsivity has been a neglected aspect in corrections research, especially with regard to the effects within a popular correctional treatment modality (cognitive-behavioral treatment). Although staff at many programs realize they should assess responsivity or barriers to treatment, they typically fail to take the next step and match the offenders to staff and programming to overcome these barriers. The lack of matching might help to explain why participation in this program resulted in a significant increase in cognitive distortions and antisocial behaviors.

We found that offenders who had a greater number of responsivity factors (or a lot of "issues") were less likely to benefit from the treatment and significantly reduce their cognitive distortions. It is important to note that 
the models were also run to determine the effects of the various individual responsivity factors on reductions in cognitive distortions. Depression was the only individual responsivity characteristic that was related to differences in cognitive distortions. It is surprising that those who were depressed experienced a greater change in the distortions of Blaming Others, Stealing, and the overall How I Think score. This is opposite of what was predicted. The other responsivity characteristics were not significant predictors of outcomes. That is, individually, intelligence, personality, abuse, and self-esteem did not predict the difference in the cognitive distortions. It should be noted that our measure of sexual abuse, that is, whether it was recorded in their file, is problematic. For example, only $3.6 \%$ of offenders in this sample had confirmation of a history of sexual abuse. What is of importance, however, is that taken together these factors were significant predictors in the difference in the antisocial attitudes. Thus, it might be the combination of responsivity factors that night hinder the success in treatment as measured by the difference in preand posttest scores of cognitive distortions and antisocial behaviors. That is, offenders who have more "issues" might be less amenable to treatment.

There are two policy implications here worth noting. First, more assessment needs to be completed on offenders prior to the treatment. Offenders with lots of "issues" such as low IQ, low self-esteem, depression, certain personality type (e.g., neurotics and aggressives), and a history of sexual abuse might require a different treatment approach. They might need to have some of these issues addressed prior to treatment. This might be especially important with regard to low self-esteem, history of sexual abuse, and depression. For various reasons, offenders with these issues might not be able to participate fully in the treatment. Second, with regard to low IQ and certain personality types, a cognitive-behavioral program that is conducted primarily in groups might not be effective for these types of offenders. Offenders with low IQ might not be able to grasp the information or understand some of the concepts. Certain personality type individuals such as a neurotic offender might not be able to feel comfortable or participate in a group treatment approach.

This study examined whether responsivity factors were related to the intermediate goal of a cognitive-behavioral treatment program for male offenders. The goal then was to reduce cognitive distortions and antisocial attitudes of offenders. We found that a combination of "issues" or responsivity characteristics was indeed related to whether the program "worked" for male offenders.

\section{Note}

1. Data on previous abuse were derived from the clients' files by the researcher. 


\section{References}

Andrews, D. A., \& Bonta, J. (1999). The psychology of criminal conduct. Cincinnati, OH: Anderson.

Andrews, D. A., Bonta, J., \& Hoge, R. D. (1990). Classification for effective rehabilitation: Rediscovering psychology. Criminal Justice and Behavior, 17, 19-52.

Andrews, D. A., Zinger, I., Bonta, R. D., Gendreau, P., \& Cullen, F. T. (1990). Does correctional treatment work? A psychologically informed meta-analysis. Criminology, 28, 369-404.

Antonowicz, D. H., \& Ross, R. R. (1994). Essential components of successful rehabilitation programs for offenders. International Journal of Offender Therapy and Comparative Criminology, 38, 97-104.

Barriga, A. Q., \& Gibbs, J. C. (1996). Measuring cognitive distortions in antisocial youth: Development and preliminary validation of the How I Think Questionnaire. Aggressive Behavior, 22, 333-343.

Bonta, J. (1995). The responsivity principle and offender rehabilitation. Forum on Corrections Research, 7(3), 34-37.

Bonta, J. (1996). Risk-needs assessment and treatment. In A. T. Harland (Ed.), Choosing correctional options that work: Defining the demand and evaluating the supply (pp. 18-32). Thousand Oaks, CA: Sage.

Catell, R. B., \& Catell, A. K. (1963). Culture fair intelligence test. Champagne, IL: Institute for Personality and Ability Testing.

Fechner-Bates, S., Coyne, J. C., \& Schwenk, T. L. (1994). The relationship of self-reported distress to psychopathology. Journal of Consulting and Clinical Psychology, 62, 550-559.

Freud, S. (1953). A general introduction to psychoanalysis. New York: Perma.

Garrett, C. (1985). Effects of residential treatment on adjudicated delinquents: A metaanalysis. Journal of Research in Crime and Delinquency, 22(4), 287-308.

Grant, J. (1965). Delinquency treatment in an institutional setting. In H. Quay (Ed.), Juvenile delinquency research and theory (pp. 263-297). Princeton, NJ: Van Nostrand.

Hollin, C. (1990). Cognitive behavioral interventions with young offenders. New York: Pergamon.

Izzo, R., \& Ross, R. (1990). Meta-analysis of rehabilitation programs for juvenile delinquents: A brief report. Criminal Justice and Behavior, 17, 134-142.

Jennings, W., Kilkenny, R., \& Kohlberg, L. (1983). Moral development theory and practice for youthful and adult offenders. In W. Laufer \& J. Day (Eds.), Personality theory, moral development and criminal behavior (pp. 281-355). Lexington, MA: Lexington Books.

Jesness, C. (1988). Jesness Inventory Classification System. Criminal Justice and Behavior, $15,78-91$.

Jesness, C. (1996). The Jesness Inventory manual. North Tonawanda, NY: Multi-Health Systems.

Johnson-Listwan, S. (2001). Personality and criminal behavior: Reconsidering the individual. Unpublished doctoral dissertation, University of Cincinnati, Cincinnati, $\mathrm{OH}$.

Jones, P. (1996). Risk prediction in criminal justice. In A. T. Harland (Ed.), Choosing correctional options that work: Defining the demand and evaluating the supply (pp. 33-68). Thousand Oaks, CA: Sage.

Kennedy, S., \& Serin, R. (1997, April). Treatment responsivity: Contributing to effective correctional programming. ICCA Journal, pp. 46-52.

Lewinson, P. M., Seeley, J. R., Roberts, R. E., \& Allen, N. B. (1997). Center for Epidemiological Studies Depression Scale (CESD) as a screening instrument for depression among communityresiding older adults. Psychology and Aging, 12(2), 277-287. 
Lipsey, M. (1990). Juvenile delinquency treatment: A meta-analytic inquiry into the variability of effects. Paper prepared for the Research Synthesis Committee of the Russell Sage Foundation.

Listwan, S. J., Sperber, K., Spruance, L., \& Van Voorhis, P. (2004). High anxiety offenders in correctional settings: It's time for another look. Federal Probation, 68(1), 43-50.

Little, G. L. (2001). Meta-analysis of MRT recidivism research on post-incarceration adult felony offenders. Cognitive-Behavioral Treatment Review, 10(3-4), 4-6.

Lowenkamp, C., \& Latessa, E. (2004). Understanding the risk principle: How and why correctional interventions can harm low-risk offenders. Topics in Community Corrections, 3-7.

Radloff, L. S. (1977). The CESD Scale: A self-report depression scale for research in the general population. Applied Psychological Measurement, 1(3), 385-401.

Robinson, D., Grossman, M., \& Porporino, F. (1991) Effectiveness of the cognitive skills training program: From pilot to national implementation (Research Brief B-07). Ottawa: Correctional Service of Canada, Research and Statistics Branch.

Rosenburg, M. (1979). Conceiving the self. New York: Basic Books.

Ross, R., \& Fabiano, E. A. (1985). Time to think. Johnson City, TN: Institute of Social Science and Arts.

Ross, R. R., Fabiano, E. A., \& Ewles C. D. (1988). Reasoning and rehabilitation. International Journal of Offender Therapy and Comparative Criminology, 32, 29-35.

Spon, R. (1999). Corrective Thinking treatment manual: Charting a new course curriculum. Retrieved from http://www.truthought.com

Sullivan, C., Grant, M. Q., \& Grant, J. D. (1957). The development of interpersonal maturity: Applications to delinquency. Psychiatry, 20, 373-385.

Van Voorhis, P. (1994). Psychological classification of the adult male prison inmate. New York: State University of New York Press.

Van Voorhis, P. (1997). An overview of offender classification systems. In P. Van Voorhis, M. Braswell, \& D. Lester (Eds.), Correctional counseling and rehabilitation (pp. 81-110). Cincinnati, OH: Anderson.

Warren, M. (1983). Application of interpersonal maturity theory to offender populations. In W. Laufer \& J. Day (Eds.), Personality theory, moral development, and criminal behavior (pp. 23-50). Lexington, MA: Lexington Books.

Yochelson, S., \& Samenow, S. E. (1976). The criminal personality volume 1: A profile for change. New York: Jason Aronson. 